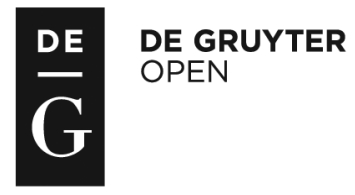

Administration, vol. 64, nos 3/4 (2016), pp. 45-58

doi: 10.1515/admin-2016-0024

\title{
Place leadership, governance and power
}

\author{
Markku Sotarauta \\ School of Management, University of Tampere, Finland
}

\begin{abstract}
There is an emerging consensus that place leadership is the missing piece in the local and regional development puzzle. In this context, leadership is a hidden form of agency, shadowed by such visible forms of influence as structures and formal institutions, as well as development programs and plans. This article argues that one of the most central issues in a study of place leadership is to analyse the relationships between governance, power and place leadership. The governance arrangements are undoubtedly important, as they dictate the kind of resources and positions provided to regional development work, and thus they also enable, as well as constrain, the many efforts of regional champions to exercise power in complex development processes. It is argued here that revealing how place leadership is enacted in different places and times would allow us to flesh out novel aspects about the eternal questions of how and why some places are able to adapt strategically to ever-changing social, economic and environmental circumstances while others fail to do so. Additionally, deeper investigations of place leadership would hopefully allow us to provide policymakers and practitioners with added insight on the ways to make regional development policies and practices not only more strategic but also effective. This paper elaborates the conceptual link between place leadership, governance and power.
\end{abstract}

Keywords: Place, leadership, power, governance, territory 


\section{Introduction}

There is a growing body of literature indicating that place leadership is the least understood piece in the regional development puzzle (Beer \& Clower, 2014; Hambleton, 2015; Sotarauta et al., forthcoming). Curiously, in the lively and flourishing field of regional development studies and practice, the concept of leadership is not spontaneously used, in spite of the fact that many studies suggest its importance.

Sotarauta (2016) argues that, in regional studies, leadership is a hidden form of agency, shadowed by such visible forms of influence as structures and formal institutions, as well as development programs and plans. Interestingly, even those actors who can retrospectively be identified as having taken a lead in various development efforts rarely reflect their leadership experiences or mention other influential individuals (Sydow et al., 2011). Rather, they speak about collective efforts or the importance of development strategies. Simultaneously, the media and upper levels of policymaking are not as hesitant to praise, often falsely, 'those individual leaders who made the change'. There is indeed a need to fill the gap between the misleading heroic leadership discourse and the actual, but shadowed, influence in order to better understand how regional development processes are led.

This article argues that one of the most central issues in a study of place leadership is to analyse the relationships between governance, power and place leadership. The governance arrangements are undoubtedly important, as they dictate the kind of resources and positions provided to regional development work, and thus they also enable, as well as constrain, the many efforts of regional champions to influence complex development processes. It is argued here that revealing how place leadership is enacted in different places and times would allow us to flesh out novel aspects about the eternal questions of how and why some places are able to adapt strategically to everchanging social, economic and environmental circumstances while others fail to do so. Additionally, deeper investigations of place leadership would hopefully allow us to provide policymakers and practitioners with added insight on the ways to make regional development policies and practices not only more strategic but also effective. This paper elaborates the conceptual link between place leadership, governance and power. It first discusses the relationship between governance and leadership, and then moves on to scrutinise place leadership and power. 


\section{Governance and leadership}

There is no shortage of studies and writings, in several fields of inquiry, about such systems of local, regional, national and transnational governance that would support various organisations in their efforts to simultaneously compete in, cooperate in and construct functioning networks for a more balanced approach to regional development. A gradual erosion of the traditional modes of government and bases of political and economic power has fuelled this process (Pierre, 2000). Additionally, as the long-prevailing modes of governance and action have not been capable of tackling an increasingly networked global economy, and the many ecological and social issues emerging with it, new modes of governance are actively sought and constructed.

The transition from traditional forms of government to more networked modes of governance is not straightforward, and in many places the rigid structures of government and underlying attitudes persist and cause problems. Many places struggle to align governance, economy, social and ecological issues, and territory, and to find proper strategies to manage growth or decline. Paradoxically, these issues are often most pressing in the most successful and rapidly growing places (Parkinson et al., 2012). Parkinson et al. (2012) show how challenges that are created by administrative fragmentation, limited local autonomy and financial pressures at all levels may lead to competition and conflict between government authorities, which results in slow and cumbersome decision-making and a limited integration of land, transportation and economic planning. However, new forms of governance enable the adoption of more place-based approaches, at least in principle, but, in practice, in many countries the system is hovering somewhere between siloed top-down government and collaborative governance (Sotarauta, 2016). But, as Parkinson (1990, pp. 21-2) states, 'there are places where political differences lead to situations in which no coherent response, negotiation or agreement among a broad range of political and social groups is possible'. Fortunately, there also are places where coherent place leadership is a central part of a well-functioning governance system, and vice versa (Parkinson, 1990; Parkinson et al., 2012; Stimson et al., 2009; Stough, 2001). As governance structures both constrain and enable leadership processes, place leadership cannot be examined as a separate entity. Rather, it should be considered as something that is central to a specific governance system (Beer, 2014; Sotarauta \& Beer, 2016), and, 
in its own way, place leadership responds to shifts from government to governance (Rhodes, 2000).

Leadership has been studied extensively in the context of relatively single-valued corporations and other organisations. But regional development and related governance systems pose a tremendous challenge to any study focusing on leadership, not to mention leadership practices, as they are by definition multi-actor and, as such, multi-value and multi-vision constellations. Multi-actor regional development and traditional forms of government do not go particularly well together, as there is a need to move from siloed and fragmented development efforts towards more long-term and enduring combinations of different actors and their differing action logics.

Many of the leadership theories and practices developed for single organisations simply do not have much to offer for regional development. In regional development, capability to steer the process, rather than designing an optimal organisation or strategy, is the key to strategic success (MacNeill \& Steiner, 2010; Sotarauta, 2016). Leadership through increasing interdependence and plurality differs significantly from the leadership in single organisations as, by necessity, it is based on the ability to lead a heterogeneous bunch of actors towards 'third solutions' that go beyond their individual ambitions, though acknowledging and respecting them. This kind of pluralistic and overlapping field of actors cannot be led by some external third party, which would be able to influence it from the outside. The leadership is the effect of different actors on each other and on themselves (Kickert et al., 1997). In this kind of setting, cognitive diversity is accepted, as well as the options for cooperation and conflict arising from it. What follows is that place leadership is approached essentially as a political process and not as a technocratic procedure.

Countries with centralised systems of government do not support place leadership as well as those countries with more devolved systems of governance (Beer \& Clower, 2014). Centralised systems tend to adopt a narrow focus on topical issues and future challenges, while, as Stimson et al. (2009) observe, devolved systems are more likely to adopt a more place-specific and strategic approach to regional development (Stimson et al., 2009). Stimson et al. (2009) argue that some of the more devolved systems, such as the US and Germany, are more benign to place leaders and their strategies of influence than the centralised systems of government in Australia and the UK. 
In centralised systems, place leaders have their hands tied, as they are fiscally dependent on the national government. Indeed, as Beer (2014) shows, place leadership in Australia is often at odds with that of centrally designed policies. He argues that Australian local leaders have to reposition themselves and their regions through resistance instead of working in collaboration with the central government. Australian place leadership is individualised and less open than, for example, its counterpart in a more institutionally rooted Finnish system of regional development, where regional needs are debated publicly and various stakeholders are more engaged. This is partly due to the more professional and shared forms of place leadership (Sotarauta \& Beer, 2016).

The role of governance systems, and the constraints they put in place, should not be overestimated. The best of the place leaders are leaders because they are able to meet the constraints confronting them and have the capacity to navigate through complex governance systems. They not only aim to mobilise actors for regional development but also work to change the rules of the game. Therefore, it is not to be concluded that place leadership would be absent in centralised systems (see, for example, Hu \& Hassink, 2016). It is simply suggested that the space and resources to manoeuvre vary across governance systems and, ultimately, we do not yet know much about the roles and strategies that place leadership may adopt in differing systems. For reasons outlined briefly in this section, place leadership ought to be seen as a particular role in a governance system (Normann, 2013), instead of as individual leaders. There is a need to adopt a systemic view on place leadership that acknowledges the restrictions of instrumental guidance of regional development, and that reaches beyond the traits and behaviours of an individual leader.

\section{Place leadership}

Regional development is essentially about a continuous struggle between visions, individual interests and ideas. It is far from easy to construct a shared vision that would provide a dispersed network of actors with a sense of direction, and thus true place leaders need to move into collaborative leadership spaces and act on behalf of wider interests (Liddle, 2012). They are in a continuous search for shared interests and opportunities to collaborate across narrow ambitions. The actors who are most influential are those able to draw the attention of others. They apply the capacity to frame thinking and may 
end up having a leadership position that often goes beyond their formal mandate. Indeed, at times they may not even have a particular mandate in a particular developmental context. However, to be able to truly influence and bring about change, they need to earn an influential position in wider networks. For that purpose, place leaders are called upon to obtain access to a wide range of networks and actors relevant to their respective regions (MacNeill \& Steiner, 2010). It should be kept in mind that, more often than not, actors participate in, and contribute to, regional development efforts with their own logics, drivers, incentives and paymasters in mind. It is far from easy to find the common ground for a collective development effort in these kinds of situations.

The powers, competencies and resources needed to make a difference in regions spread among many policymakers as, by necessity, place leadership is a dispersed form of leadership. In this kind of setting leaders often influence policy development within confined formal powers, and therefore they need to reach beyond those institutions and organisations that authorise them, generating and tapping into wider networks of influence. Also, formally assigned leaders with institutional power often need to work beyond their organisations, and learn to act in vaguely defined territories that are characterised by ambiguous roles and imprecise boundaries (Liddle, 2010). Consequently, in regional development and related governance settings, formal authority does not always play as significant a role as we tend to believe (Normann, 2013; Sotarauta, 2010). Informal influence can be as significant to achieving a particular policy direction.

Place leadership is an emergent property of interacting individuals (Bennett et al., 2003). Therefore, it may often be difficult to identify the leaders and followers (Trickett \& Lee, 2010; Huxham \& Vangen, 2000). This is due to the fact that there is a tendency to mix leadership with formal authority and institutional power, and hence to overshadow more hidden and emergent sides of place leadership. Quite naturally, it is attractive for many of us to acknowledge mainly influential individuals with authority and formal positions, or to analyse the governance structures. All of this is visible, while nonassigned leaders and hidden forms of place leadership are harder to observe and analyse. Understanding the dynamics of concealed administration is as important to influencing regional policy direction.

Assigned leaders have a formal position and they are granted the authority to exercise power. They also have an organisation, resources 
and/or a mandate to work for a region. The set of assigned leaders may contain mayors and the chief executives of various local authorities and economic development agencies, and other leaders of organisations whose mission it is to boost the economic development of their respective regions. On their part, non-assigned leaders exercise other forms of influence, as their institutional position does not allow them any specific resources with which to make a difference. They gain a leadership position because of the ways in which other actors respond to their ideas and/or actions.

Simplified, there are (a) assigned leaders with a formal position whose mission is to boost regional development, but who mainly influence according to the mandate they possess and their formal instruments. These leaders do what they are supposed to do, and they lead mainly followers assigned to them in their own organisations. There are also (b) assigned leaders with a formal position to work for regional development, but who continuously aim to reach beyond their authorisation to influence broader spheres of relevant activity. They do what they are supposed to do but they also consciously aim to exercise influence by, with and through other actors. On their part, (c) non-assigned leaders do not have a formal role in regional development but, in spite of that, they are willing and able to take leadership positions in wider networks of influence. These leaders do what they are not supposed to do but what they feel needs to be accomplished (Sotarauta, 2016).

In regional development, however, the line between assigned and non-assigned leadership is fine. Assigned leaders may turn out to be non-assigned, if they aim to reach actors beyond the familiar field of activity while others simply do not respond. Conversely, non-assigned leaders may gain formal authority and a more recognised position if they can earn the respect of others and thus influence the development work more broadly. All in all, non-assigned leaders aim to influence assigned leaders or other actors with power and resources, who, for their part, have a mandate and the resources to boost economic development. More often than not, assigned leaders also work through, with and by other actors.

\section{Interpretive power and place leadership}

Place leaders aim to influence wider networks to generate something new in their respective places, and by necessity they are required to work through the many clashes between distinct cultures and agendas, 
as well as asymmetric power relationships (Burfitt \& MacNeill, 2008). Place leadership is not only about generating new networks and structures for regional development, but also about social uncertainty and ambiguity. It is virtually impossible to understand place leadership without understanding the ways in which different sources of power come together in the many fields of regional development. Interestingly, in these kinds of settings, power is not only a cause of leadership but also a consequence of it. Leaders can become truly influential only if followers follow (Riggio et al., 2008).

There is a whole variety of ways to conceptualise and study power. Wrong (1997, p. 2) provides a basic point of departure by defining it as 'the capacity of some persons to produce intended and foreseen effects on others'. Ideally, in regional development, place leaders are not aiming to break the resistance of other actors - to cause them to do something they would not otherwise do (Paloheimo \& Wiberg, $2005)$ - but to induce them to willingly do things they would not otherwise do (Sotarauta, 2016).

An extensive empirical study carried out in Finland on leadership in urban and regional development revealed that in a world of indirect influence (i.e. regional development) the combination of interpretive and network power seems to be a way in which to mould the preferences of the other actors (see Sotarauta, 2009). Place leaders often work to construct a collective belief of what should be done, how and why in the region, and for that purpose they aim to influence the combinations of actors and their thinking. The conviction is that resources and formal decisions will follow innovative mind-sets and networks. This kind of shaping of individual preferences via values, norms and ideologies reminds us about the power of social systems and structures (Foucault, 1980; Parsons, 1986).

In its own way, place leadership aims to work through belief systems. Belief systems define the arena for many actors, affect institutional design and are frequently institutions in themselves. Often they are simply taken for granted. It is believed here that the true place leaders do not take them for granted but aim to challenge other actors and their thinking patterns. And here the highest form of power resides in the ways in which collective thinking is influenced, and how challenges are defined and framed for action.

Essentially, place leaders must be able to draw the attention of other actors and then translate it into the issues that need to be faced collectively (Heifetz, 1994). In other words, they exercise interpretive power. Interpretive power does not refer to efforts to seek consensus, 
but to a never-ending endeavour to create fertile soil for concerted thinking and a collective push to transform the institutions for the future instead of the past. The ability to frame the issues discussed, to lead sense-making processes and hence to influence which issues are on the agenda, and also who is involved in the communication, brings a significant amount of power to an actor who can actually do all of this. Influence draws upon understanding the needs and resources of a whole series of different organisations with different objectives and strategies. Here, place leaders with strong interpretive power are called for, as other actors need to comprehend the purpose of transformative measures so that they will focus less on the person and more on the meaning of the new action. Various partners need to be actively involved in the belief-making process.

Empirical studies carried out in Finland have shown that belief formation is central during the mobilisation of networks and finding directions for them, as well as to influencing the perceptions of the network participants (Sotarauta, 2009; 2010; 2016; see also Kickert et al., 1997). Place leaders frame their networks of influence by introducing new ideas to them and by providing network members with new interpretations of old ideas (Kickert et al., 1997). The aim is not necessarily to find a shared vision directly, as is often assumed, but to detect denominators that would allow collaboration to achieve both individual and shared objectives, and eventually come up with a shared vision. Belief formation gives shape to emerging development needs and strategies, and hence also to collective efforts, and it has great influence on the alignment of various forms of engagement. The problem is that often our capabilities for recognising the open-ended exploratory parts of the development and innovation processes are not sufficiently well developed. We simply do not have a vocabulary for them.

Even though interpretive power has emerged as important, the relevance of resource and institutional power should not be undermined. This is because the observations presented here are drawn from studies focusing on those local and regional development champions who, in spite of their formal assignment, do not have abundant resources or powerful enough formal positions in a governance structure to draw upon. Therefore, they work to influence legitimate holders of power of the entire local/regional development system, local government, the corporate world and/or academia. They work to create a new context and interpretation for regional development, and hence 'to build a new storyline for a development play'. 
In sum, place leaders are capable, among other things, of identifying dominant discourses and interpretations framing regional development, and of generating a new dialogue leading to a new hegemonic discourse on much needed changes, and collective action stemming from them. Leading by interpretation is central, as collective action calls for making sense of the ambiguous world, as well as of complex public policies and corporate strategies. Therefore, place leaders aim to seek out the differences and similarities in the various actors' interpretations, working to synthesise different interpretations and the goals derived from them.

In practice, place leaders convene groups of actors for dialogue. They mediate information and they also create new knowledge. They interpret, for example, academic thinking and talk to firms, and vice versa. All this both requires interpretive power and builds on it. Place leaders need to be able to speak with many interest groups in their 'own language', rather than alienating themselves from the relevant networks by speaking a language the rest of the pack does not understand or by using a rationale that has no meaning to people. Other key tasks include improving the coordination between fragmented groups of actors, fostering and organising collaboration, and influencing, if possible, the division of labour within the networks.

\section{Conclusions}

In the interest of identifying the opportunities and solving the many problems faced by a region, there is a need to work through the many organisational and institutional boundaries and to pool fragmented competencies, powers and resources. For that purpose, the various goals and strategies of individual organisations need to be made as parallel as possible by inter-organisational learning, communication and negotiation, and this calls for enhanced leadership capabilities. The challenge is that place leadership is far from a linear and straightforward act of influencing. It is characterised by fragmented and/or shared actions, events and incidents among a whole series of organisations and/or several leaders, rather than by processes that simply flow from the 'top down', from some kind of a control centre to followers (Sotarauta et al., forthcoming). By necessity, place leadership is a multi-scalar, dynamic and interactive process between national, local and regional government actors, firms, universities, research institutions, and public and/or semi-public development agencies. As such, it is embedded in regional development processes 
where not all people who are leaders are formally recognised as such, while sometimes people with formal positions may exercise only little leadership, or none at all.

Leadership practices regarding how much development efforts revolve around formal leadership vary between governance systems and, to some degree, also within them. It is undeniable that formal leaders dealing with regional development are faced with a wider range of actors than previously, and the many networks are seasoned with more varied mixes of global, national and local players, as well as increased technical complexity. These are the reasons why leaders are increasingly called on to stimulate and lead change agendas without having the formal power to do so, but with the responsibility to generate something new. If the distributed assets can be mobilised to serve both joint and individual needs, it may be possible to forge a collaborative dynamic development effort, which is something more than an individual actor can demonstrate alone.

From a place leadership perspective, the many regional development plans and/or strategies are not designed to guide different actors directly. Many such plans are in fact arenas for discussions, battles and quarrels (Healey, 1997). In the hands of skilled leaders, however, they may be powerful leadership tools. In the hands of bureaucratic planners, unfortunately, they may turn out to be hollow planning cycles without any true impact on regional development.

Understanding the kind of place leadership introduced in this paper may be essential in broader efforts to understand and explain how, and for what purpose, actors influence each other for regional development and/or their self-interests. It follows that shared strategic intentions are, in practice, combinations of the goals and visions of individual actors. Therefore, an ability to identify individual goals and to find and create the common denominators between them - the 'third solutions' - seems to be a prerequisite for shared strategic intentions. Shared strategic intention is based on imagining the future between visions. Here, appreciating 'other visions' is crucial, and learning about other actors' thinking patterns, and especially the different views and perceptions of futures, forms the core skill of a generative leader. What often appears as collective action is in practice a complex, constantly evolving process between a network and its members that place leaders mould. Place leadership is thus future seeking, but not future defining. Place leadership is about living and coping with continuously emerging phenomena, complex 
networks and often strange incidents, and not about aiming to control them.

\section{Acknowledgement}

This article partially draws on ideas expressed in earlier articles and books by the same author, especially Sotarauta (2016).

\section{References}

Beer, A. (2014). Leadership and the governance of rural communities. Journal of Rural Studies, 34, 254-62.

Beer, A., \& Clower, T. (2014). Mobilising leadership in cities and regions. Regional Studies, Regional Science, 1 (1), 10-34.

Bennett, N., Wise, C., Woods, P. A., \& Harvey, J. A. (2003). Distributed leadership: A review of literature. London: National College for School Leadership/ The Open University.

Burfitt, A., \& MacNeill, S. (2008). The challenges of pursuing cluster policy in the congested state. International Journal of Urban and Regional Research, 32 (2), 492-505.

Foucault, M. (1980). Power/knowledge: Selected interviews and other writings, 1972-77. New York: Pantheon Books.

Hambleton, R. (2015). Place-based collaboration: Leadership for a changing world. Administration, 63 (3), 5-25.

Healey, P. (1997). Collaborative planning. Shaping places in fragmented societies. London: Macmillan Press Ltd.

Heifetz, R. A. (1994). Leadership without easy answers. Cambridge, MA: The Belknap Press of Harvard University Press.

Hu, X., \& Hassink, R. (2016). Place leadership with Chinese characteristics? A case study of the Zaozhuang coal-mining region in transition. Regional Studies. doi: 10.1080/00343404.2016.1200189

Huxham, C., \& Vangen, S. (2000) Leadership in the shaping and implementation of collaboration agendas: How things happen in a (not quite) joined-up world. Academy of Management Journal, 43 (6), 1,159-75.

Kickert, W. J. M., Klijn, E.-H., \& Koppenjan, J. F. M. (Eds). (1997). Managing complex networks: Strategies for the public sector. London: Sage Publications Ltd.

Liddle, J. (2010). The new public leadership challenge. International Journal of Public Sector Management, 24 (1), 97-8.

Liddle, J. (2012). Collaborative leadership in city-regions: Achieving social, economic, environmental objectives in partnership. In M. Sotarauta, I. Horlings \& J. Liddle (Eds), Leadership and change in sustainable regional development (pp. 37-59). Abingdon: Routledge. 
MacNeill, S., \& Steiner, M. (2010). Leadership of cluster policy: Lessons from the Austrian province of Styria. Policy Studies, 31 (4), 441-55.

Normann, R. (2013). Regional leadership: A systemic view. Systemic Practice and Action Research, 26 (1), 23-38.

Paloheimo, H., \& Wiberg, M. (2005). Politiikan perusteet [Politics] (3rd edn). Keuruu: WSOY.

Parkinson, M. (1990). Leadership and regeneration in Liverpool: Confusion, confrontation or coalition? In D. Judd \& M. Parkinson (Eds), Leadership and urban regeneration (pp. 241-57). Newbury Park, CA: Sage.

Parkinson, M., Meegan, R., Karecha, J., Evans, R., Jones, G., Sotarauta, M., Ruokolainen, O., Tosics, I., Gertheis, A., Tönko, A., Hegedüs, J., Illés, I. Lefèvre, C., \& Hall, P. (2012). Second tier cities in Europe: In an age of austerity why invest beyond the capitals? Liverpool: Liverpool John Moores University.

Parsons, T. (1986). Power and the social system. In S. Lukes (Ed.), Power. Readings in social and political theory (pp. 94-143). New York: New York University Press.

Pierre, J. (Ed.) (2000). Debating governance: Authority, steering and democracy. Oxford: Oxford University Press.

Rhodes, R. A. W. (2000). Governance and public administration. In J. Pierre (Ed.), Debating governance: Authority, steering and democracy (pp. 54-90). Oxford: Oxford University Press.

Riggio, R. E., Chaleff, I., \& Lipman-Blumen, J. (2008). The art of followership: How great followers create great leaders and organizations. San Francisco: Jossey-Bass (a Wiley imprint).

Sotarauta, M. (2009). Power and influence tactics in the promotion of regional development: An empirical analysis of the work of Finnish regional development officers. Geoforum, 40 (5), 895-905.

Sotarauta, M. (2010). Regional development and regional networks: The role of regional development officers in Finland. European Urban and Regional Studies, 17 (4), 387-400.

Sotarauta, M. (2016). Leadership and the city: Power, strategy and networks in the making of knowledge cities. Abingdon, Oxon: Routledge.

Sotarauta, M., \& Beer, A. (2016). Governance, agency and place leadership: Lessons from a cross-national analysis. Regional Studies. doi: 10.1080/00343404.2015.1119265

Sotarauta, M., Beer, A., \& Gibney, J. (forthcoming). Making sense of leadership in urban and regional development. Regional Studies.

Stimson, R., Stough, R. R., \& Salazar, M. (2009). Leadership and institutions in regional endogenous development. Northampton: Edwar Elgar.

Stough, R. (2001). Endogenous growth theory and the role of institutions in regional economic development. In $\mathrm{Z}$. Acs (Ed.), The emergence of the knowledge economy: A regional perspective. New York: Springer.

Sydow, J., Lerch, F., Huxham, C., \& Hibbert, P. (2011). A silent cry for leadership: Organizing for leading (in) clusters. The Leadership Quarterly, 22, 328-43. 
Trickett, L., \& Lee, P. (2010). Leadership of 'subregional' places in the context of growth. Policy Studies, 31 (4), 429-40.

Wrong, D. H. (1997). Power: Its forms, bases, and uses. New Brunswick: Transaction Publishers. 